\title{
Sjögren's Syndrome with Primary Biliary Cirrhosis, Complicated by Transverse Myelitis and Malignant Lymphoma
}

Takeru Wakatsuki, Masayuki Miyata, Shyoichiro Shishido, Tomohiro Suzuki, Hiromasa Ohira, Masae Kokubun, Yukio Sato*, Teiji Yamamoto** and Reiji KaSuKaWA*

\begin{abstract}
A 53-year-old woman with Sjögren's syndrome (SS) and primary biliary cirrhosis (PBC) complicated by transverse myelitis (TM) and malignant lymphoma (ML) is reported. TM has been described only in seven cases of primary SS, including three with PBC and four without PBC. The features of SS associated with PBC and complicated by TM were less typical compared with those seen in SS without PBC complicated by TM. This case is the first report of a case with SS, PBC, TM and ML. SS in association with PBC is, in general, overlooked, but such cases must be investigated with great caution for extraglandular complications. (Internal Medicine 39: 260-265, 2000)
\end{abstract}

Key words: primary Sjögren's syndrome, necrotizing vasculitis, antineural antibody, antiphospholipid syndrome

\section{Introduction}

Primary Sjögren's syndrome (SS) is considered to be the most common disease among the chronic systemic rheumatic diseases. The clinical manifestations are classified into glandular and extraglandular, or exocrine and nonexocrine (1). Clinical manifestations, such as dryness of the skin and mucosa, internal organ involvement, proliferative lymphocytic disorders, thyroiditis and inflammatory vascular diseases appear either concomitantly or more often, independently. Transverse myelitis is a rarely encountered complication in SS. We present here the first case of SS with primary biliary cirrhosis (PBC) complicated by transverse myelitis and malignant lymphoma.

For editorial comment, see p 193.

\section{Case Report}

A 53-year-old woman was admitted to our Department of Internal Medicine II, Fukushima Medical University Hospital in April 1995 for the investigation of liver dysfunction, and excessive thirst and dry eyes which were first noticed in 1994. She had been diagnosed as having chronic keratoconjunctivitis in 1994.

\section{The main laboratory data at presentation were as follows}

Serum CRP: $0.1 \mathrm{mg} / \mathrm{dl}$ (normal: $<0.3$ ); WBC: $3,600 / \mathrm{mm}^{3}$ (normal: 2,800-8,800); $\mathrm{Hb}: 11.4 \mathrm{~g} / \mathrm{dl}$ (normal: 11.6-14.0); Blood platelets: $13.3 \times 10^{4} / \mathrm{mm}^{3}$ (normal: $14.7-34.1 \times 10^{4}$ ); Serum AST: 56 IU/l (normal: 10-30), ALT: 32 IU/l (normal: 629), LDH: 506 IU/l (normal: 250-410), ALP: 250 IU/l (normal: 125-335), TB: $1.5 \mathrm{mg} / \mathrm{dl}$ (normal: 0.4-1.2), DB: $0.4 \mathrm{mg} /$ dl (normal: 0.2-0.4), TTT: $31.3 \mathrm{KU}$ (normal: $1-5$ ) and ZTT: 27.7 KU (normal:1-12); anti-hepatitis $\mathrm{C}$ virus ( $\mathrm{HCV}$ ) antibody: positive; HCV RNA (probe method): $19 \mathrm{mEq} / l$; antimitochondrial antibodies: $\times 80$ (normal: $<\times 80$ ); anti-pyruvate dehydrogenase complex M2 antibody: positive; anti-branched chain $\alpha$-keto acid dehydrogenase complex M2 antibody: positive; antinuclear antibody: $<80$ (cytoplasmic pattern) (normal: $<\times 80$ ); The titers of anti-SS-A and SS-B antibodies were 7.2 $\mathrm{U} / \mathrm{ml}$ (normal: $<7$, borderline: $7-20$, positive: $\geq 20$ ) and $0 \mathrm{U} / \mathrm{ml}$ (normal $<10$, borderline: 10-25, positive: $\geq 25$ ), respectively, by enzyme immunoassay; Rheumatoid factor: $61 \mathrm{U}(<5)$. Both anticardiolipin antibody and anti-CL $\beta 2$ GP-1 antibody were negative. The lupus anticoagulant was not measured, but APTT was 35.8 seconds (normal: 31-45).

Decreased salivation was diagnosed in the Department of Otorhinolaryngology of our hospital, but quantitative determination of the volume of saliva was not performed. Histological analysis of a minor salivary gland in an oral mucosal biopsy revealed sparse lymphocytic infiltration and fibrosis around the minor salivary glands. Schirmer's test of both eyes revealed $0 \mathrm{~mm}$ wetting in 5 minutes. The tear fluid breakup time (2) was 3 seconds for both eyes (normal: $>30$ seconds). The rose

From *the Department of Internal Medicine II, **the Department of Internal Neurology, Fukushima Medical University School of Medicine, Fukushima Received for publication June 1, 1999; Accepted for publication November 11, 1999

Reprint requests should be addressed to Dr. Masayuki Miyata, the Department of Internal Medicine II, Fukushima Medical University School of Medicine, 1 Hikarigaoka, Fukushima 960-1295 
bengal test (van Bijsterveld score) was 9 for corneal erosion.

She complained of a sudden onset of numbness, pain in the lower extremities and dizziness while walking in March 1996. In the meantime, she felt impaired sensation of temperature while bathing, but she did not have a fever consistently. She was referred to the Department of Orthopedics of our hospital and was admitted to that department in April 1996.

\section{The neurological findings were as follows}

Impaired sensation of touch, pain and temperature was noted below the Th3 5 level and numbness below the level of Th7. The manual muscle test was $4 / 5$ in the right lower extremity. The knee and ankle jerks were exaggerated. No pathologic reflex was noted. Urine retension and constipation were noted.
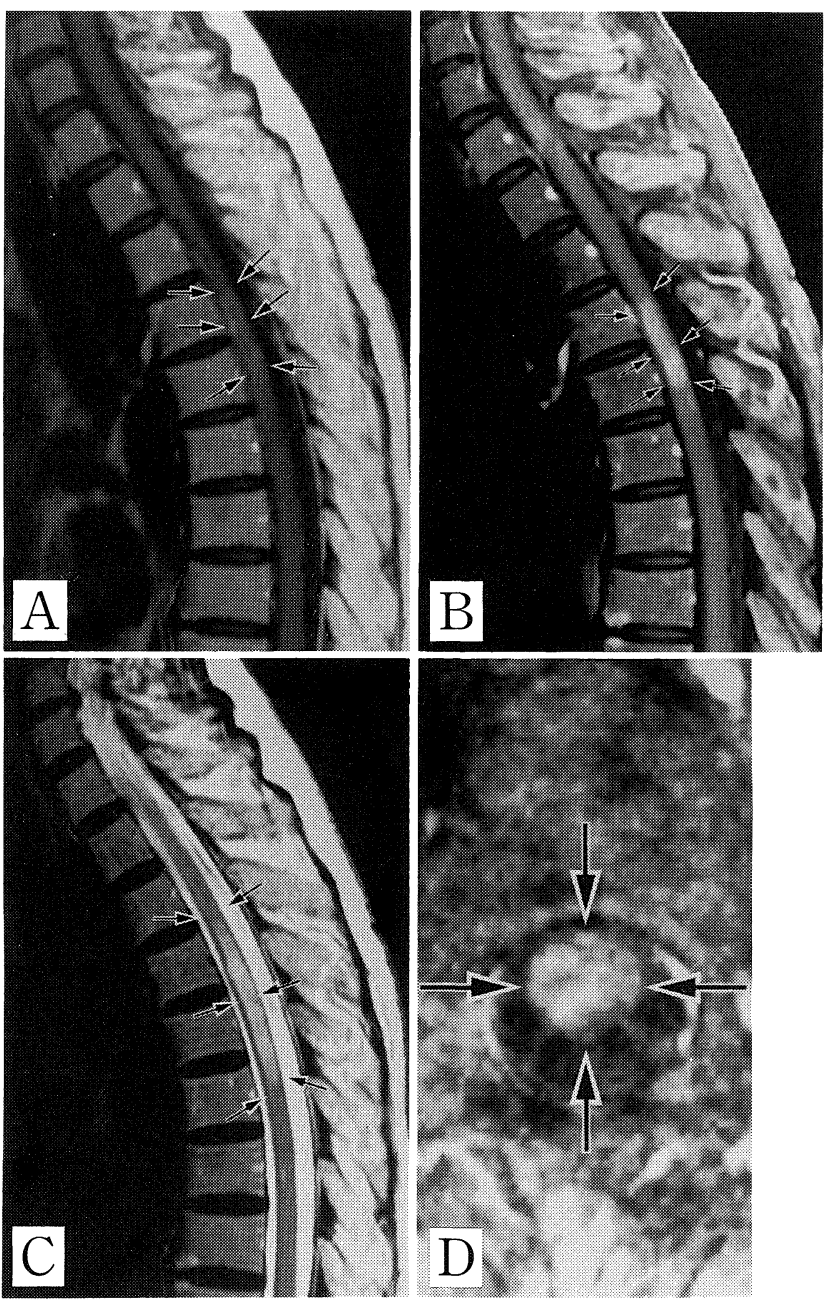

Figure 1. Findings of magnetic resonance imaging of the spinal cord. Sagittal images are shown in A-C. The area of Th3 6 is slightly swollen (arrows), and isointense in T1-weighted images (T1WI), hyperintense in T2WI and enhanced by gadolinium in T2WI as shown in A, B and C, respectively. A transverse T2WI enhanced by gadolinium is shown in $\mathrm{D}$.

\section{The findings on cerebrospinal fluid examination were as fol- lows}

Pandy reaction: positive; Nonne-Apelt reaction: negative; glucose: $51 \mathrm{mg} / \mathrm{dl}$; total protein: $37 \mathrm{mg} / \mathrm{dl}$ (normal: <40); cell count: $27 / 3$ fields (mononuclear cells: $89 \%$, polymorphonuclear cells: $11 \%$ ); IgG: $173 \mathrm{mg} / \mathrm{dl}$ (normal: $<3$ ).

Multiple sclerosis was considered as a differential diagnosis, but she lacked disturbance of visual activity and was too old to be diagnosed as having multiple sclerosis. The serum vitamin B12 level was $790 \mathrm{pg} / \mathrm{ml}$ (249-938) and the antibody for HTLV-1 was negative in both the serum and cerebrospinal fluid.

The findings of magnetic resonance imaging of the spine are shown in Fig. 1. The area of Th4 6 was slightly swollen and isointense in T1-weighted images (T1WI), hyperintense

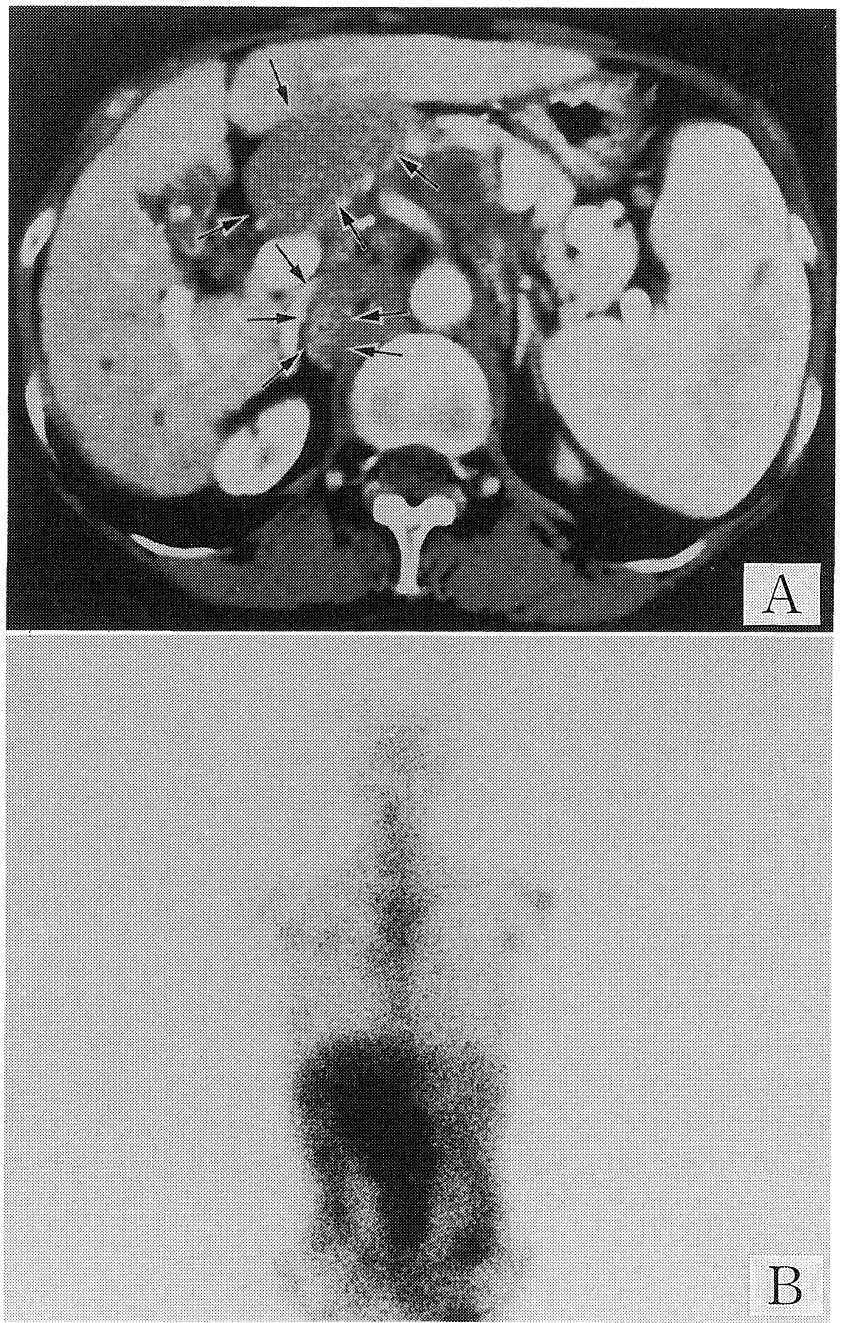

Figure 2. Findings of CT and gallium scintigraphy. CT scan revealed swelling of paraaortic and parapancreatic lymph nodes as shown in A (arrows). Gallium scintigraphy revealed accumulation of gallium in cervical, axillary, inguinal, infrahepatic to parapancreatic and paraaortic regions as shown in $B$. 

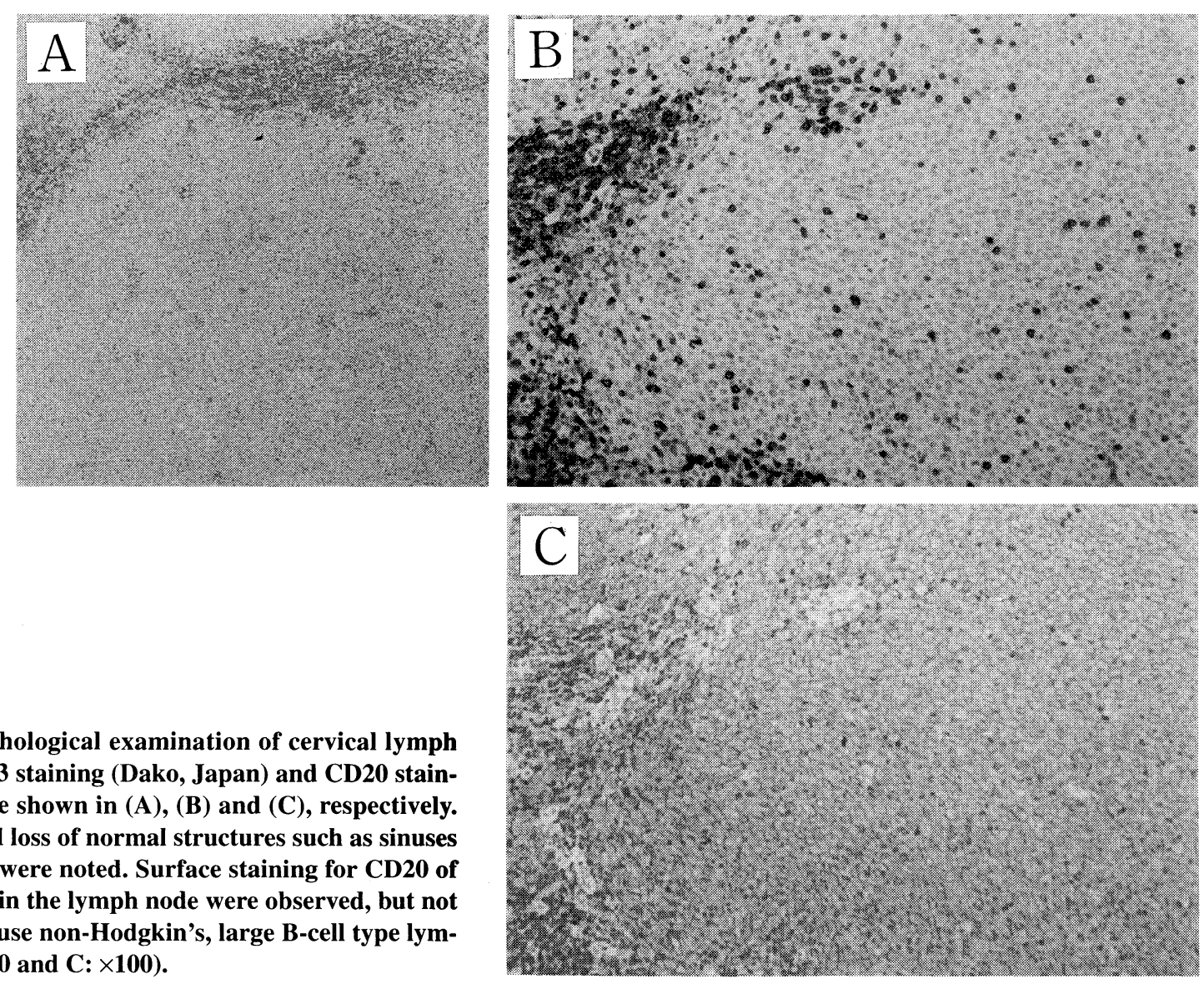

Figure 3. Histopathological examination of cervical lymph node. HE staining, CD3 staining (Dako, Japan) and CD20 staining (Dako, Japan) were shown in (A), (B) and (C), respectively. The diffuse growth and loss of normal structures such as sinuses and lymphoid follicles were noted. Surface staining for CD20 of lymphocytes clustered in the lymph node were observed, but not for CD3, revealing diffuse non-Hodgkin's, large B-cell type lymphoma $(\mathrm{A}: \times 40, \mathrm{~B}: \times 100$ and $\mathrm{C}: \times 100)$.

in T2WI and enhanced by gadolinium in T2WI. These findings are indicative of an inflammatory rather than a tumorous lesion.

She was administered $1,000 \mathrm{mg} /$ day of methylprednisolone for 3 days under the presumptive diagnosis of inflammatory myelopathy. After a couple of months, the neurological findings such as the decrease in sensation and muscle weakness of the right lower extremity improved, but the sense of numbness below the level of Th7 remained. She was discharged in the month of June 1996.

She was hospitalized again in September 1998, at the Department of Internal Medicine II of our university for the investigation of swollen lymph nodes. A CT scan of the abdomen revealed swelling of the paraaortic and parapancreatic lymph nodes as shown in Fig. 2A. Gallium scintigraphy revealed accumulation of gallium in the cervical, axillary, inguinal and infrahepatic to parapancreatic and paraaortic regions as shown in Fig. 2B. Cervical lymph node and liver biopsy revealed diffuse non-Hodgkin's, large B-cell type lymphoma (NHL) as shown in Fig. 3 and PBC stage II as shown in Fig. 4.

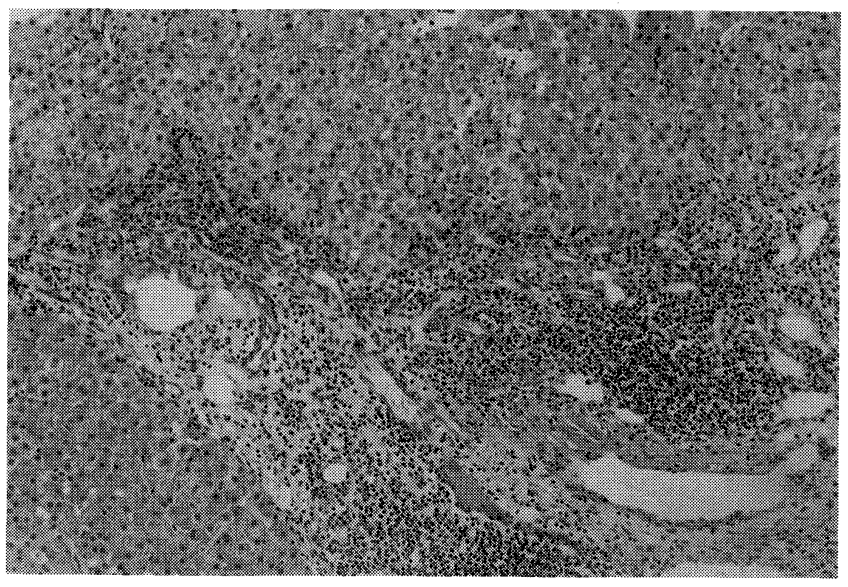

Figure 4. Histopathological examination of liver. Moderate infiltration of mononuclear cells and destroyed small bile ducts in the enlarged portal area were noted. The intensity of ductal proliferation was slight and bridging necrosis was not found. These findings were compatible with PBC stage II (HE staining, $\times 180$ ).

\section{Discussion}

The present patient had dry eyes with corneal erosion and dry mouth without definite histologic evidence of sialoadeni-

tis. The titers of anti-SS-A antibody and anti-SS-B antibody were borderline and normal, respectively. According to the European criteria for the diagnosis of SS (3), the sicca syn- 
SS in PBC with Myelitis and ML

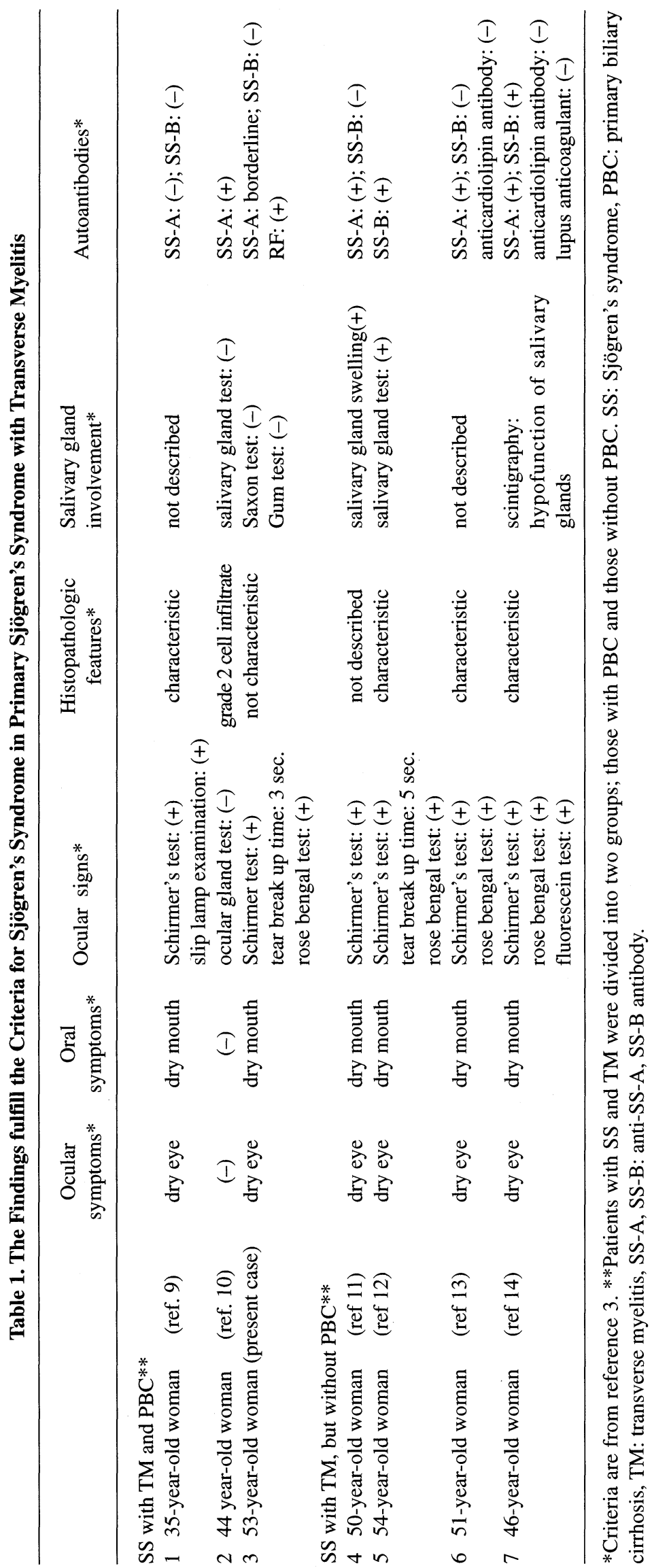




\section{WAKATSUKI et al}

drome in this patient cannot be diagnosed as definite SS, but can be diagnosed as probable SS. This patient also had liver dysfunction with $\mathrm{HCV}$ and antimitochondrial antibodies. Histopathological examination clearly revealed the liver dysfunction as being due to $\mathrm{PBC}$ and not due to $\mathrm{HCV}$.

We thus examined the relationship between transverse myelitis and malignant lymphoma, and the above-mentioned SS with PBC. In regard to the relationship between hepatitis viruses and transverse myelitis, hepatitis type $\mathrm{B}$ virus (HBV) has been implicated in transverse myelitis, and the molecular mimicry of HBV and myelin basic protein was proposed as being the cause of transverse myelitis in HBV carriers and following HBV vaccination (4-6). There are also reports of hepatitis type A virus in association with transverse myelitis $(7,8)$. However, to our knowledge, there have been no reports of $\mathrm{HCV}$ in association with transverse myelitis.

SS is classified into primary and secondary types. Although the central nervous system involvement in connective tissue vascular diseases such as systemic lupus erythematosus and polyarteritis nodosa is well known, transverse myelitis has been described in only seven cases with primary SS (9-14) as shown in Table 1.

Cases 1-3 have primary SS as well as PBC. Among these three cases, Case 1 was negative for anti- SS-A and SS-B antibodies, Case 2 did not have positive results on ocular and salivary gland tests and Case 3 , the present case, has a borderline elevation in the titer of anti-SS-A antibody, is negative for antiSS-B antibody, and the histopathological findings in the minor salivary glands were not typical for SS.

On the other hand, cases 4-7 having primary SS more satisfactorily fulfil the European criteria for the diagnosis of SS (3) than those patients with PBC. As a matter of fact, the mean number of findings which fulfil the criteria in patients with primary SS with $\mathrm{PBC}$ and transverse myelitis and in patients with primary SS without $\mathrm{PBC}$ and with transverse myelitis was 3 and 5.5 , respectively.

We wish to propose that, when associated with PBC and complicated by transverse myelitis, SS exhibits less features of the syndrome, although this would be difficult to conclude from this study because of the limited number of cases with SS exhibiting the complication of transverse myelitis. Comparing the number of primary SS patients with $\mathrm{PBC}$ with those without $\mathrm{PBC}$, transverse myelitis seems to be more frequent in patients of SS with PBC.

The transverse myelitis could be caused in patients with SS by 4 mechanisms: [1] necrotizing vasculitis (11), [2] ganglionitis with T-cell infiltration $(15,16)$, [3] antineural antibodymediated neural cytotoxicity (17) and [4] vascular thrombosis. Here, ganglionitis was seen in the dorsal root and by hyperintensity on T2WI, but it was not enhanced by gadolinium in T2WI (16). In another report, a patient with transverse myelitis did not have antineural antibody and patients with antibody were manifested by neurologic findings such as polyneuropathy, organic brain syndrome, migraine and sensory neuronopathy (17). The present patient did not have anticardiolipin antibody or anti-CL $\beta 2$ GP-1 antibody, and
APTT was within the normal limit. From these findings, we suppose that this patient with SS was complicated by transverse myelitis due to necrotizing vasculitis.

Later, the present patient developed NHL. Patients with SS have a 43.8 times higher probability of developing malignant lymphoma than expected from the rates of cancer prevailing among women of comparable age in the general population (18). Patients with primary SS have a greater risk of developing NHL compared with those with secondary SS (19). Although monoclonality of lymphocytes does not unequivocally indicate malignancy, it is considered to be a precursor of the development of NHL in SS. Polyclonal lymphoproliferation characterizing SS might in some instances transform into monoclonal proliferation, and then go on to become malignant (20). In developing malignant lymphoma, monoclonal proliferation in the background of polyclonal proliferation of lymphocytes occurs, resulting in deterioration of the features of SS. We suppose that this transformation from polyclonal into monoclonal proliferation might be one of the reasons why she exhibits less features of SS.

It should be mentioned that PBC can also be complicated by malignant lymphoma. A few reports describe the development of malignant lymphoma in the liver $(21,22)$, but it is a very rare condition; moreover, malignant lymphoma of extrahepatic sites such as in our case is extremely rare (23). Among those patients of PBC complicated by malignant lymphoma, the association between PBC and malignant lymphoma is discussed in relation to SS complicating PBC (24).

This is the first report of a case with PBC, SS, transverse myelitis and malignant lymphoma. SS in PBC is, in general, overlooked, but such cases must be investigated with great caution for extraglandular and glandular complications.

Acknowledgements: We are indebted to Ms. E. Omata for her help in preparing the manuscript.

This work was supported in part by a grant from the Foundation for the Research Committee for the Treatment of Early Rheumatoid Arthritis, supported by the Japanese Ministry of Health and Welfare.

\section{References}

1) Manthorpe R, Asmussen K, Oxholm P. Primary Sjögren's syndrome: Diagnostic criteria, clinical features, and disease activity. J Rheumatol 24 Suppl 50: 8-11, 1997.

2) Records RE. Tear film, Biomedical Foundations of Ophthalmology. Vol. II. Duane D, Jaeger E. Eds. Philadelphia, Harper \& Row, 1985: 1-22.

3) Vitali C, Bombardieri S, Moutsopoulos HM, et al. Preliminary criteria for the classification of Sjögren's syndrome: Results of a prospective concerted action supported by the European Community. Arthritis Rheum 36: 340-347, 1993.

4) Trevisani F, Gattinara GC, Caraceni P, et al. Transverse myelitis following hepatitis B vaccination. J Hepatol 19: 317-318, 1993 (letter).

5) Jahnke U, Fisher EH, Alvord EC Jr. Sequence homology between certain viral protein and proteins related to encephalomyelitis and neuritis. Science 229: 282-284, 1985.

6) Herroelen L, de Keyser J, Ebinger G. Central-nervous-system demyelination after immunisation with recombinant hepatitis B vaccine. Lancet 338: 1174-1175, 1991 (see comments).

7) Breningstall GN, Belani KK. Acute transverse myelitis and brainstem encephalitis associated with hepatitis A infection. Pediatr Neurol 12: 169- 


\section{SS in PBC with Myelitis and ML}

$171,1995$.

8) Vahidy F, Kazmi K, Rab SM. Transverse myelitis and hepatitis in varicella. J Trop Med Hyg 92: 295-296, 1989.

9) Rutan G, Martinez AJ, Fieshko JT, Van Thiel DH. Primary biliary cirrhosis, Sjögren's syndrome, and transverse myelitis. Gastroenterology 90: 206-210, 1986.

10) Linardaki G, Skopouli FN, Koufos C, Moutsopoulos HM. Subclinical multisystemic autoimmunity presenting as a progressive myelopathy. Lupus 6: 675-677, 1997.

11) Alexander GE, Provost TT, Stevens MB, Alexander EL. Sjögren's syndrome: central nervous system manifestations. Neurology 31: 1391-1396, 1981.

12) Konttinen YT, Kinnunen E, von Bonsdorff M, et al. Acute transverse myolopathy successfully treated with plasmapheresis and prednisone in a patient with primary Sjögren's syndrome. Arthritis Rheum 30: 339$344,1987$.

13) Harada $T$, Ohashi $T$, Miyagishi R, et al. Optic neuropathy and acute transverse myelopathy in primary Sjögren's syndrome. Jpn J Ophthalmol 39: $162-165,1995$.

14) Kaneko Y, Suwa A, Nakajima A, et al. A case of primary Sjögren's syndrome accompanied by transverse myelitis. Ryumachi 38: 600-604, 1998 (in Japanese, Abstract in English).

15) Griffin JW, Cornblath DR, Alexander E, et al. Ataxic sensory neuropathy and dorsal root ganglionitis associated with Sjögren's syndrome. Ann Neurol 27: 304-315, 1990.

16) Sobue G, Yasuda T, Kumazawa K, Yamamoto K, Mitsuma T. MRI dem- onstrates dorsal column involvement of the spinal cord in Sjögren's syndrome-associated neuropathy. Neurology 45: 592-593, 1995.

17) Moll JW, Markusse HM, Pijnenburg JJ, Vecht CJ, Henzen-Logmans SC. Antineuronal antibodies in patients with neurologic complications of primary Sjögren's syndrome. Neurology 43: 2574-2581, 1993.

18) Kassan SS, Thomas TL, Moutsopoulos HM, et al. Increased risk of lymphoma in sicca syndrome. Ann Intern Med 89: 888-892, 1978.

19) Valesini G, Priori R, Bavoillot D, et al. Differential risk of non-Hodgkin's lymphoma in Italias: patients with primary Sjögren's syndrome. J Rheumatol 24: 2376-2380, 1997.

20) Anaya JM, McGuff HS, Banks PM, Talal N. Clinicopathological factors relating malignant lymphoma with Sjögren's syndrome. Semin Arthritis Rheum 25: 337-346, 1996.

21) Goldin R, Sayer J, Wilkins M, Price P, Thomas H. Primary liver lymphoma associated with primary biliary cirrhosis. Histopathology 22: 184 185, 1993.

22) Prabhu RM, Medeiros LJ, Kumar D, et al. Primary hepatic low-grade Bcell lymphoma of mucosa-associated lymphoid tissue (MALT) associated with primary biliary cirrhosis. Mod Pathol 11: 404-410, 1998.

23) Viteri A, Vernace SJ, Schaffner F. Extrahepatic malignancy in chronic liver disease: Report of six cases. Gastroenterology 71: 1075-1078, 1976.

24) Ijichi $S$, Iwata $S$, Une $F$, Tara M, Igata $A$. B cell malignancy associated with Sjögren syndrome and primary biliary cirrhosis: a case report and review. Rinsho Ketsueki 28: 911-916, 1987 (in Japanese, Abstract in English). 